\title{
Developmental Course and Risk Factors of Physical Aggression in Late Adolescence
}

\author{
Marit Henriksen ${ }^{1,4,8}$ (1) $\cdot$ Marit Skrove ${ }^{3,4}$. Gry Børmark Hoftun ${ }^{1,5} \cdot$ Erik R. Sund $^{2,6,7} \cdot$ Stian Lydersen ${ }^{3}$. Wan-Ling Tseng ${ }^{8}$. \\ Denis G. Sukhodolsky ${ }^{8}$
}

Published online: 27 August 2020

(c) The Author(s) 2020

\begin{abstract}
This study examined risk factors of physical aggression during transition from early to late adolescence using a two-wave longitudinal study. Specifically, we examined if risk factors in early adolescence predict physically aggressive behavior starting in late adolescence and why some adolescents desist physical aggressive behavior while others do not. The study sample consisted of 2289 Norwegian adolescents (1235 girls) who participated in the Young-HUNT1 study (mean age 14.5) and the follow-up study 4 years later, Young-HUNT2 study (mean age 18.4). One in six young adolescents reported engaging in physical fights. Moreover, physical aggression in early adolescence was significantly associated with male gender, attention problems, academic problems, being bullied, drinking alcohol, and smoking. Male gender and heavy drinking during early adolescence increased the risk for newly emerging aggressive behavior in late adolescence, whereas heavy drinking during early adolescence was a predictor for persistent versus desisting aggressive behavior in late adolescence.
\end{abstract}

Keywords Physical aggression $\cdot$ Physical fighting $\cdot$ Adolescence $\cdot$ Risk factors $\cdot$ Longitudinal

Marit Henriksen

Marit.Henriksen@ntnu.no; Marit.Henriksen@yale.edu

1 Department of Clinical and Molecular Medicine, Faculty of Medicine and Health Science, The Norwegian University of Science and Technology, 7491 Trondheim, Norway

2 Department of Public Health and Nursing, Faculty of Medicine and Health Science, The Norwegian University of Science and Technology, Trondheim, Norway

3 Department of Mental Health, Faculty of Medicine and Health Science, The Norwegian University of Science and Technology, Trondheim, Norway

4 Child and Adolescent Psychiatric Clinic, St. Olav's University Hospital, Trondheim, Norway

5 Children's Clinic, St Olav's University Hospital, Trondheim, Norway

6 Faculty of Nursing and Health Sciences, Nord University, Levanger, Norway

7 Nord-Trøndelag Hospital Trust, Levanger Hospital, Levanger, Norway

8 Child Study Center, Yale University School of Medicine, New Haven, CT, USA

\section{Introduction}

Physical aggression in childhood and adolescence represents a major clinical and public health concern. Thus, in a population study in the United States in 2017, 23.6\% of high school students (grade 9 to 12 ) reported participating in a physical fight in the preceding year [1]. At the global level, interpersonal violence is the fourth leading cause of death among adolescents aged 15 to 19 , with a $5.5 \%$ mortality rate [2]. Physical aggression and delinquency can have long lasting negative consequences for the perpetrators and the victims. Perpetrators of physical aggression are shown to have an increased risk for later physical violence and crimes [3, 4], school drop-out [4, 5], substance abuse [5], future mental, and physical health problems and economic difficulties [6]. Victims, in addition to the physical injuries, have an increased risk of mental health problems, educational and economic difficulties, involvement in crimes [7], and externalizing problems [8].

From a developmental perspective, the type and prevalence of physically aggressive behavior change with age. In typically developing youth, the prevalence of physical aggression peak at around age 3 and decrease from childhood to adolescence, as children acquire more advanced 
cognitive, social and language skills, and learn to regulate emotions and use alternative conflict resolution strategies [9-11]. Some children continue to display high levels of physical aggression throughout their childhood and adolescence [12-14]. Nagin and Tremblay [3], in a sample of 1037 boys followed from age 6 to 15 years old, identified four trajectories of physical aggression: chronic/persisting aggression (4\%), high near-desisting (28\%), moderate desisting (52\%) and no physical aggression trajectory (17\%). Since this seminal study, these developmental trajectories of physical aggression have been well replicated in other studies [10, $13,15,16]$, although the number of trajectories and number of children in each category varies as a function of sample characteristics and aggression measurements.

Empirical studies have identified multiple correlates and risk factors of physical aggression in adolescence [17, 18]. Both girls and boys can initiate aggressive behavior, but boys display more physical aggression than girls $[9,11,13$, 16]. Mental health disorders are associated with physical aggression, most notably disruptive behavior disorders and attention-deficit/hyperactivity disorder (ADHD), but also anxiety and depression [19-21]. Longitudinal studies have found ADHD symptoms to predict physical aggression [3, 5, 22], physical aggression to predict depression [23, 24], and anxiety to protect against aggression [25]. Physical aggression is also associated with academic difficulties [26, 27], and low self-esteem [28]; however, some research indicates that high self-esteem may also be associated with physically aggressive behavior [29].

Regarding social factors, family characteristics including single-parent household and divorced parents have been associated with elevated risk for physical aggression [10, $16,17,30]$. While some studies present evidence that having divorced parents is a risk factor for later physical aggression [31, 32], others do not [10]. Peer factors, such as peer rejection, bullying, and loneliness, commonly co-occur with physical aggression in adolescence [33-36], and bullying victimization in adolescence has been linked to later violence [37].

During adolescence, developmentally normative changes in social relationships, including decreasing parental supervision and increasing influence of peers, may also elevate risk for aggression [31, 38]. Similarly, engagement in new, risky behaviors may impact aggressive behavior. For example, increases in alcohol drinking and intoxication, drug use and smoking have been associated with physical aggression in adolescence [5, 39-42]. In a study on alcohol consumption and aggression (verbal and physical) within a large sample of college students $(n=6282)$, a direct relationship between alcohol and aggression was found, indicating that increased alcohol use increases risk for aggression [43].

Compared to the large number of studies examining risk factors of physical aggression in childhood and adolescence, much less is known about the risk factors of physical aggression in late adolescence, during the important transition to adulthood. Longitudinal studies of aggression that follow children into young adulthood often focus on broad categories of delinquency [44, 45], rather than specific acts of physical aggression such as fighting. However, studies on physical aggression in childhood and adolescence have shown that physical aggression is a specific and separate dimension of disruptive behavioral problems [46], and physical aggression in late adolescence and young adulthood can also occur outside of delinquency trajectories, for example in relation to intimate partner violence [47]. In addition, few studies have examined the risk factors and courses of physical aggression from early to late adolescence. During this time, adolescents are faced with important developmental tasks, such as identity formation, separating from parents, and developing autonomy and intimacy with others [48, 49] at the same time as parents' supervision decreases. Although physical aggression generally declines with increasing age, the specific characteristics of the adolescent period may place some individuals at risk for the onset of physically aggressive behavior during this developmental phase. Two studies support the trend of increasing physically aggressive behavior over the course of adolescence [15, 31]. However, one of these studies did not examine risk factors of courses of aggression, and the other study used a broader measure of aggression that did not distinguish between physical and verbal aggression (e.g., verbal threats).

\section{The Aims of the Study}

This study addresses these gaps in the literature by examining risk factors of physical aggression over a key developmental stage, early to late adolescence. Using a population-based prospective, longitudinal cohort study, we measured a common form of physical aggression in adolescents-fighting among peers-at two timepoints four years apart, corresponding to early (13-16) and late adolescence (17-20). The consequences of participating in physical fighting differs by age. The objective of the study was to examine the correlates of this serious and dangerous form of aggression in early adolescence and its course from early to late adolescence. We wanted to examine if known risk factors, anxiety and depression, loneliness, self-esteem problems, attention problems, reading and writing problems, being bullied, parent's marital status, alcohol intoxication, and smoking, in early adolescence can predict why some adolescents have an onset of physical aggression in late adolescence, as this group has received less focus in the literature. We also wanted to examine if the same risk factors can explain why aggressive behavior desists in some adolescents and not others. From previous studies we know that a small group of 
children display physical aggressive behavior throughout childhood, adolescence, and into adulthood [12-14]. Identifying risk factors that separate persisting from desisting physical aggression in adolescence, is important for the development of efficient interventions hindering physical aggressive behavior into adulthood. Higher cumulative risks are associated with higher levels of physical aggression [50, 51]. The prospective, longitudinal cohort study, The Young-HUNT study, offers a unique opportunity to use a large non-clinical adolescent population of boys and girls to investigate several risk factors and how they affect courses of physical aggression in adolescence.

\section{Methods}

\section{Study Population and Design}

All residents aged 13 years and older in the county of Nord-Trøndelag, Norway were invited to participate in The Nord-Trøndelag Health Study (HUNT) that was conducted between 1995 and 1997 [52, 53]. The population was stable and homogenous and therefore suitable for epidemiological, longitudinal studies [54]. Adolescents aged 13 to 19 years old were invited to participate in Young-HUNT1 (YH1), the first wave (time 1) of the study (response rate $88.1 \%$ ). Adolescents who were $13-16$ years old in YH1 were then invited to participate in the follow-up study Young-HUNT2 (YH2) four years later (time 2). A total of 2399 adolescents participated (response rate $76.8 \%$ ) in both waves. The sample for the present study consisted of 2289 subjects. Subjects with missing values on the dependent variable (physical fighting) $(\mathrm{n}=110)$ were excluded. The study is Data Protection Impact Assessment (DPIA) approved by The Norwegian University of Science and Technology (NTNU) and approved by the Regional Committee for Medical and Health Research Ethics (REK) in Norway (ref. 2017/1208/REK-midt).

\section{Measures}

At time 1 and time 2, the subjects completed a self-report questionnaire in a classroom setting at school. Subjects not in school got the questionnaire by mail and were asked to fill out and return it. The questionnaire included questions about physical and psychological health, family variables, lifestyle, use of medication and health service, school difficulties, and pubertal status. The original questionnaire translated to English is available at the HUNT Web page: (https://www.ntnu.edu/hunt/data/que).

\section{Dependent Variable}

To study physical aggression, adolescents were asked to indicate whether they had been in a physical fight using a four-point response scale (Never, Sometimes, Often, and Very often). The item was a part of the 14-item School Adjustment Questionnaire (designed by the Norwegian Institute of Public Health) assessing behaviors at school or in relation to school. Although the time frame was not specified in the item itself, this item was embedded in the questionnaire about current health-related issues that were queried for the period of the past 12 months. It was therefore assumed that children rated their aggressive behavior for this period. The scale`s psychometric properties and validation are described in previous studies $[55,56]$. The majority of adolescents in YH1 and YH2 endorsed Never on this question (see Table 1). Of the 2289 participants, 23 children (1.0\%) endorsed Often and $9(0.4 \%)$ children endorsed Very often in $\mathrm{YH} 1$; in $\mathrm{YH} 2$, 12 children $(0.5 \%)$ endorsed Often and $11(0.5 \%)$ children endorsed Very often. Due to the highly skewed distribution, the physical aggression variable was dichotomized as $\mathrm{No}$ aggression for all subjects who responded Never and Physical aggression for all subjects who endorsed Sometimes, Often, or Very often. To examine the developmental course of aggression, we used the dichotomized physical aggression variable in $\mathrm{YH} 1$ and $\mathrm{YH} 2$ and generated a variable with four courses of physical aggression: (1) the non-aggression group (no physical fighting in YH1 or YH2), (2) the desisting aggression group (physical fighting in YH1, but not $\mathrm{YH} 2$ ), (3) the late adolescent aggression group (physical fighting in $\mathrm{YH} 2$, but not $\mathrm{YH} 1$ ), and (4) the persistent aggression group (physical fighting in $\mathrm{YH} 1$ and $\mathrm{YH} 2$ ).

\section{Independent Variables}

Mental Health Variables Symptoms of anxiety and depression were assessed using a shortened and previously vali-

Table 1 Prevalence of physical fighting inYH1 and YH2

\begin{tabular}{clllll}
\hline \multicolumn{5}{c}{} & \multicolumn{2}{l}{ PF in YH2 } & & \\
\cline { 2 - 6 } & Never & Sometimes & Often & Very often & Total \\
\hline $\begin{array}{c}\text { PF in YH1 } \\
\text { Never }\end{array}$ & 1793 & 89 & 5 & 4 & $\begin{array}{c}1891 \\
(82.6 \%)\end{array}$ \\
$\begin{array}{c}\text { Some- } \\
\text { times }\end{array}$ & 271 & 86 & 4 & 5 & $366(16.0 \%)$ \\
$\begin{array}{c}\text { Often } \\
\text { Very } \\
\text { often }\end{array}$ & 10 & 9 & 2 & 2 & $23(1.0 \%)$ \\
Total & 2080 & 186 & 12 & 11 & 2289 \\
& $(90.9 \%)$ & $(8.1 \%)$ & $(0.5 \%)$ & $(0.5 \%)$ & $(100 \%)$ \\
\hline
\end{tabular}

$Y H 1$ Young-HUNT1, $Y H 2$ Young-HUNT2, $P F$ physical fighting 
dated five-item scale (SCL-5) [57, 58] derived from the Hopkins Symptom Checklist for anxiety and depression (SCL-25). The subjects were asked to rate, on a four-point scale (Never, Sometimes, Often, and Very often) how much they had been bothered by the following thoughts and feelings during the last 14 days: Been constantly afraid and anxious, Felt tense or uneasy, Felt hopelessness when you think of the future, Felt dejected or sad, and Worried too much about various things. The items were summed and averaged, with higher scores representing more symptoms of anxiety and depression. Cronbach`s alpha for SCL-5 was 0.77 . Loneliness was indexed by the item Do you feel lonely? on a five-point scale (Very often, Often, Sometimes, Seldom, and Very seldom or never).

A short version of the Rosenberg Self-Esteem Scale [59, 60] was used to measure self-esteem. The subjects were asked to rate on a four-point scale (Strongly agree, Agree, Disagree, and Strongly Disagree) the following four items: I take a positive attitude toward myself, I certainly feel useless at times, I feel I do not have much to be proud of, and I feel that I'm a person of worth, at least on an equal plane with others. The positively phrased items were reverse scored. The items were summed and averaged, with higher scores representing lower self-esteem. Cronbach`s alpha for the Self-esteem scale was 0.71 .

School Variables Items from the School Adjustment Questionnaire with a 4-point response scale (Never, Sometimes, Often, and Very often) were used to index attention problems and bullying. Attention problems were assessed by two items: Have difficulties concentrating during class and Can`t manage to be calm/ sit still during class. The two items were averaged, with higher scores representing more problems with attention. Experience with being bullied was assessed by one item: Are teased/harassed by other students? Subjects were asked How often do you feel your reading or writing skills are below the level of the tasks you do at school and/or in your spare time? (separate item for reading and for writing) with a five-point response scale (Never, Very seldom, Sometimes, Often, and Always). The items were summed and averaged, with higher scores representing more problems with reading and writing.

Family Variable Subjects were asked Are your parents separated or divorced, or have they lived separately for more than one year? Parent's marital situation was dichotomized into Parents living together and Parents separated or divorced.

Substance Use Subjects were asked Have you ever drunk so much alcohol that you felt intoxicated (drunk)? with a 5-point response scale (No, never, Yes, once, Yes, 2-3 times, Yes, 4-10 times, and Yes, more than 10 times). Responses were further categorized into three categories: Never been drunk,
Been drunk 1 to 10 times, and Been drunk more than 10 times. Subjects were also asked Do you smoke? and were defined as current smokers if they responded Yes to smoking daily or occasionally.

\section{Analyses}

The distribution of the four categories of responses to the physical fighting variable in $\mathrm{YH} 1$ and $\mathrm{YH} 2$ is shown in a cross tabulation. In the remaining analyses, the three categories Sometimes, Often, and Very often were merged, giving the dichotomy aggressive versus non-aggressive. Descriptive statistics for the correlates are displayed for the total sample in the study, the aggressive vs the non-aggressive adolescents in YH1, and the four courses of physical aggression. The correlates used here and in the later analyses were: mental health variables (anxiety and depression symptoms, loneliness, and self-esteem problems), school variables (attention problems, reading- and writing problems, and being bullied), parent's marital status, and substance use (alcohol intoxication and smoking), all from YH1.

In a cross-sectional analysis, we used logistic regression with physical aggression in YH1 as dependent variable and correlates in YH1. The correlates were first examined one at a time only adjusted for the covariates age and gender (Model 1 ), and then jointly (Model 2). The course of physical aggression was studied using multinomial logistic regression with the four courses of physical aggression from $\mathrm{YH} 1$ to $\mathrm{YH} 2$ as a four-category dependent variable. The OR in multinomial logistic regression has the same interpretation as the OR in binary logistic regression. Risk factors were first examined independently, only adjusted for age and gender (Model 1), and then all included for a fully adjusted model (Model 2). Choice of reference group in the analyses were based on the aim being studied. When examining what separates the nonaggression group from the late adolescent aggression group, in terms of risk factors, the non-aggression group was the reference group. When examining what separates the desisting aggression group from the persistent aggression group, the desisting aggression group was the reference group. Two-sided $\mathrm{p}$ values $<0.05$ were used to indicate statistical significance. Missing values were handled using available case analysis, that is, each analysis included the cases with available data on the variables included in the analysis. All statistical analyses were conducted using Stata for Windows, version 15 (STATA Corp, College Station, TX, USA). 


\section{Results}

\section{Prevalence of Physical Aggression}

The sample consisted of 1235 girls (46.1\%) and 1054 boys $(54.0 \%)$. Mean age was 14.5 years (SD 0.91) in YH1 (Time 1), and 18.4 years (SD 0.80) in YH2 (Time 2). In YH1, 1891 (82.6\%) subjects responded that they Never participate in physical fights while $398(17.4 \%)$ responded Sometimes, Often or Very often. In YH2, 2080 (90.9\%) subjects responded that they Never participate in physical fights while 209 (9.1\%) responded Sometimes, Often or Very often. (see Table 1). Higher percentage of boys engaged in physical aggression than girls at both timepoints (YH1-85.9\% versus $14.1 \%$, YH2 $-82.3 \%$ versus $17.7 \%)$.

Of the 2289 adolescents, 1793 adolescents (78.3\%) were in the non-aggressive group, 287 adolescents (12.5\%) were in the desisting aggression group, 98 adolescents (4.3\%) were in the late adolescent aggression group, and 111 adolescents (4.9\%) were in the persistent aggression group. The sex distribution was 1151 girls $(64.2 \%)$ versus 642 boys (35.8\%) in the non-aggression group, 47 girls (16.4\%) versus 240 boys (83.6\%) in the desisting aggression group, 28 girls (28.6\%) versus 70 boys (71.4\%) in the late adolescent aggression group, and 102 boys (91.9\%) versus 9 girls (8.1\%) in the persistent aggression group. See Table 2 for more characteristics of the study subjects.

\section{Cross-Sectional Correlates of Physical Aggression in Early Adolescence}

Results of the logistic regression analysis with physical aggression in $\mathrm{YH} 1$ as the dependent variable and the risk factors assessed at YH1 as correlates are presented in Table 3. The ORs show that younger age, male sex, anxiety and depression, loneliness, low self-esteem, attention problems, reading and writing problems, being bullied, drinking alcohol, and smoking were all associated with physical aggression in early adolescence (Model 1). The largest ORs were for male sex (OR 10.04, 95\% CI [7.45, 13.52]) and being drunk more than 10 times (OR 8.08, 95\% CI [4.60, 14.17]). Parent's marital status was not associated with physical aggression in YH1. When adjusting for all the correlates in the fully adjusted model, anxiety and depression, loneliness, and self-esteem problems were not significantly associated with physical aggression in $\mathrm{YH} 1$.
Risk Factors for Physical Aggression Starting in Late Adolescence

Results from the multinomial logistic regression analysis with the late adolescent aggression group as the dependent variable and the non-aggression group as the reference group are presented in Table 4 . When adjusting for age and sex (Model 1), the results showed that male gender (OR 4.46, 95\% CI [2.85, 6.99]), attention problems (OR 1.56, 95\% CI [1.08, 2.67]), alcohol use (alcohol intoxications between 1 to 10 times, OR 2.46, 95\% CI [1.50, 4.15], and more than 10 times, OR 4.13, 95\% CI $[1.44,11.83]$ ), and smoking (OR $3.49,95 \%$ CI [1.92, $6.35]$ ) in early adolescence were statistical significant risk factors for onset of physical fighting in late adolescence. In the fully adjusted model (Model 2), male gender, alcohol intoxications between 1 and 10 times, and smoking remained statistic significant.

\section{Risk Factors for Persistent Physical Aggression During Adolescence}

Results from the multinomial logistic regression analysis with the persistent aggression group as the dependent variable and the desisting aggression group as the reference group are presented in Table 4 . When only adjusting for age and sex (Model 1), the results showed that male gender (OR 2.22, 95\% CI [1.05, 4.71]) and alcohol intoxications (between 1 and 10 times, OR $2.35,95 \%$ CI $[1.33,4.14]$ and more than 10 times, OR $4.32,95 \%$ CI $[1.85,10.10])$ increased the risk of persistent aggressive behavior, relative to desisting aggressive behavior. Male gender and getting drunk between 1 and 10 times both doubled the odds of continued physical aggressive behavior during adolescence, compared to desisting aggressive behavior, whereas getting drunk more than 10 times increased the odds by four. The OR for male gender attenuated in the fully adjusted model (Model 2), while the ORs for alcohol intoxication between 1 and 10 times and more than 10 times remained statistic significant, indicating a strong predictive effect of alcohol drinking in early adolescence for persistent physical aggression during adolescence.

\section{Discussion}

In this study, we used the data from the Young-HUNT study to examine correlates of physical aggression in early adolescence and examine risk factors for physical aggression during the transition from early to late adolescence. Our results showed that younger age, male sex, anxiety and depression symptoms, loneliness, self-esteem problems, attention problems, reading and writing problems, being bullied, alcohol intoxications, and smoking were all associated with physical 
Table 2 Sample characteristics and risk factors in YH1 by total sample, physical aggression and no-aggression in YH1, and four courses of physical aggression

\begin{tabular}{|c|c|c|c|c|c|c|c|}
\hline & Total sample & $\mathrm{PA}$ in $\mathrm{YH} 1$ & No PA in YH1 & $\begin{array}{l}\text { The non-aggres- } \\
\text { sion group }\end{array}$ & $\begin{array}{l}\text { The desisting } \\
\text { aggression } \\
\text { group }\end{array}$ & $\begin{array}{l}\text { The late } \\
\text { aggression } \\
\text { group }\end{array}$ & $\begin{array}{l}\text { The persistent } \\
\text { aggression } \\
\text { group }\end{array}$ \\
\hline & $\begin{array}{l}\text { Mean (SD) or } \\
\mathrm{n}(\%)\end{array}$ & $\begin{array}{l}\text { Mean (SD) or } \\
\mathrm{n}(\%)\end{array}$ & $\begin{array}{l}\text { Mean (SD) or } \\
\mathrm{n}(\%)\end{array}$ & $\begin{array}{l}\text { Mean (SD) or } \\
\mathrm{n}(\%)\end{array}$ & $\begin{array}{l}\text { Mean (SD) } \\
\text { or } \mathrm{n}(\%)\end{array}$ & $\begin{array}{l}\text { Mean (SD) } \\
\text { or } n(\%)\end{array}$ & $\begin{array}{l}\text { Mean (SD) } \\
\text { or } \mathrm{n}(\%)\end{array}$ \\
\hline $\begin{array}{r}\text { Participants } \\
(\mathrm{n}=2289)\end{array}$ & 2289 & 398 & 1891 & 1793 (78.3) & 287 (12.5) & $98(4.3)$ & $111(4.9)$ \\
\hline $\operatorname{Age}^{a}(n=2289)$ & $14.51(0.91)$ & $14.39(0.89)$ & $14.54(0.91)$ & $14.54(0.91)$ & $14.38(0.86)$ & $14.44(0.85)$ & $14.42(0.96)$ \\
\hline \multicolumn{8}{|l|}{$\operatorname{Sex}^{b}(n=2289)$} \\
\hline Girls & $1235(46.0)$ & $56(14.1)$ & $1179(62.3)$ & $1151(64.2)$ & $47(16.4)$ & 28 (28.6) & $9(8.1)$ \\
\hline Boys & $1054(54.0)$ & 342 (85.9) & 712 (37.7) & $642(35.8)$ & 240 (83.6) & $70(71.4)$ & 102 (91.9) \\
\hline $\begin{array}{l}\text { Anxiety and } \\
\text { depression }^{\mathrm{a}} \\
(\mathrm{n}=2282)\end{array}$ & $1.37(0.43)$ & $1.38(0.44)$ & $1.37(0.43)$ & $1.37(0.43)$ & $1.39(0.44)$ & $1.36(0.45)$ & $1.37(0.46)$ \\
\hline $\begin{array}{l}\text { Loneliness }^{\mathrm{a}} \\
(\mathrm{n}=2281)\end{array}$ & $1.93(0.89)$ & $1.99(0.94)$ & $1.92(0.88)$ & $1.92(0.87)$ & $2.01(0.93)$ & $1.98(0.96)$ & $1.93(0.96)$ \\
\hline $\begin{array}{l}\text { Self-esteem } \\
\text { prob. }^{\text {a }} \\
(\mathrm{n}=2275)\end{array}$ & $1.95(0.52)$ & $1.93(0.53)$ & $1.96(0.52)$ & $1.96(0.52)$ & $1.95(0.54)$ & $1.93(0.55)$ & $1.88(0.50)$ \\
\hline $\begin{array}{l}\text { Attention prob. } \\
\quad(\mathrm{n}=2289)\end{array}$ & $1.90(0.55)$ & $2.06(0.59)$ & $1.87(0.54)$ & $1.86(0.54)$ & $2.03(0.60)$ & $1.93(0.61)$ & $2.14(0.58)$ \\
\hline $\begin{array}{l}\text { Reading and } \\
\text { writing prob. } \\
(\mathrm{n}=2210)\end{array}$ & $1.58(0.88)$ & $1.78(0.94)$ & $1.55(0.86)$ & $1.55(0.86)$ & $1.74(0.92)$ & $1.57(0.78)$ & $1.88(0.99)$ \\
\hline $\begin{array}{l}\text { Bullied }^{\mathrm{a}} \\
\qquad(\mathrm{n}=2278)\end{array}$ & $1.17(0.42)$ & $1.36(0.59)$ & $1.12(0.37)$ & $1.12(0.37)$ & $1.34(0.55)$ & $1.12(0.36)$ & $1.41(0.67)$ \\
\hline \multicolumn{8}{|l|}{$\begin{array}{l}\text { Parent`s marital } \\
\text { sit. }^{\mathrm{b}}(\mathrm{n}=2257)\end{array}$} \\
\hline Together & $1823(80.8)$ & 309 (78.0) & 1514 (81.3) & 1441 (81.6) & 228 (79.7) & $73(76.8)$ & 81 (73.6) \\
\hline $\begin{array}{l}\text { Separated or } \\
\text { divorced }\end{array}$ & 434 (19.2) & 87 (22.0) & 347 (18.7) & 325 (18.4) & $58(20.3)$ & $22(23.2)$ & $29(26.4)$ \\
\hline \multicolumn{8}{|l|}{$\begin{array}{l}\text { Alcohol } \\
\text { intoxication }^{\mathrm{b}} \\
(\mathrm{n}=2246)\end{array}$} \\
\hline Never & $1646(73.3)$ & $260(66.8)$ & 1386 (74.6) & $1327(75.2)$ & $200(71.4)$ & $59(64.2)$ & $60(55.0)$ \\
\hline $1-10$ & $501(22.3)$ & 93 (23.9) & $408(22.0)$ & $380(21.5)$ & $60(21.4)$ & $28(30.4)$ & $33(30.3)$ \\
\hline$>10$ & 99 (4.4) & $36(9.3)$ & $63(3.4)$ & $58(3.3)$ & $20(7.2)$ & $5(5.4)$ & $16(14.7)$ \\
\hline \multicolumn{8}{|l|}{$\begin{array}{l}\text { Smoking }{ }^{\mathrm{b}} \\
\quad(\mathrm{n}=2248)\end{array}$} \\
\hline No & $2001(89.0)$ & 325 (83.6) & $1676(90.2)$ & 1598 (90.6) & $236(84.3)$ & 78 (81.7) & 89 (81.7) \\
\hline Yes & 247 (11.0) & $64(16.5)$ & $183(9.8)$ & $166(9.4)$ & 44 (15.7) & $17(18.4)$ & $20(18.3)$ \\
\hline
\end{tabular}

For each variable, the number of participants with available data is shown in parenthesis

YH1 Young-HUNT1, PA physical aggression

${ }^{\mathrm{a} C}$ Continuous variables

${ }^{\mathrm{b}}$ Dichotomous variables

aggression in early adolescence. Male sex, having attention problems, and drinking alcohol and smoking cigarettes in early adolescence (mean age 14.5 years) increased the risk of emerging physical aggression in late adolescence (mean age 18.4 years), and only male sex and frequent alcohol intoxications were related to increased risk of continuing physical aggression from early to late adolescence.
Our results concerning correlates of physical aggression in early adolescence were consistent with the literature [17-20, 28, 39]. While some of the associations attenuated in the fully adjusted model, attention problems, reading and writing problems, being bullied, alcohol intoxication frequency between 1 and 10 times and more than 10 times, and smoking still were significantly associated. The strongest 
Table 3 Logistic regression to identify correlates of physical aggression in $\mathrm{YH} 1$

\begin{tabular}{|c|c|c|c|c|}
\hline & \multicolumn{2}{|l|}{ Model 1} & \multicolumn{2}{|l|}{ Model 2} \\
\hline & ORs & $95 \% \mathrm{CI}$ & ORs & $95 \% \mathrm{CI}$ \\
\hline Age & $0.85^{*}$ & {$[0.75,0.97]$} & $0.62 * * *$ & {$[0.52,0.73]$} \\
\hline \multicolumn{5}{|l|}{ Sex } \\
\hline Boys (ref = Girls) & $10.04 * * *$ & {$[7.45,13.52]$} & $12.74 * * *$ & {$[8.98,18.08]$} \\
\hline Anxiety and depression & $2.04 * * *$ & {$[1.55,2.69]$} & 1.08 & {$[0.74,1.58]$} \\
\hline Loneliness & $1.28 * * *$ & {$[1.12,1.46]$} & 0.99 & {$[0.84,1.18]$} \\
\hline Self-esteem prob & $1.72 * * *$ & {$[1.35,2.19]$} & 1.15 & {$[0.85,1.54]$} \\
\hline Attention prob & $2.39 * * *$ & {$[1.93,2.95]$} & $1.76^{* * *}$ & {$[1.38,2.26]$} \\
\hline Reading and writing prob & $1.29 * * *$ & {$[1.14,1.47]$} & $1.16^{*}$ & {$[1.01,1.33]$} \\
\hline Bullied & $2.44 * * *$ & {$[1.92,3.09]$} & $2.17 * * *$ & {$[1.65,2.85]$} \\
\hline \multicolumn{5}{|l|}{ Parent's marital sit } \\
\hline $\begin{array}{l}\text { Separated or divorced } \\
\text { (ref }=\text { Together) }\end{array}$ & 1.32 & {$[0.99,1.76]$} & 0.89 & {$[0.64,1.23]$} \\
\hline \multicolumn{5}{|l|}{ Alcohol intoxication } \\
\hline $1-10($ ref = Never $)$ & $2.01 * * *$ & {$[1.47,2.75]$} & $1.54 *$ & {$[1.08,2.21]$} \\
\hline$>10$ (ref = Never $)$ & $8.08 * * *$ & {$[4.60,14.17]$} & $4.55^{* * *}$ & {$[2.38,8.69]$} \\
\hline \multicolumn{5}{|l|}{ Smoking } \\
\hline Yes $(\mathrm{ref}=\mathrm{No})$ & $3.39 * * *$ & {$[2.33,4.93]$} & $1.78^{*}$ & {$[1.12,2.81]$} \\
\hline
\end{tabular}

Model 1-Associations for correlates and physical aggression adjusted for age in YH1 and sex. Model 2Fully adjusted model. All risk factors and covariates (age, sex) are included in the model. $n=2289$

ORs Odds Ratios, CI Confidence Interval, YH1 Young-HUNT1

$* \mathrm{p}<0.05, * * \mathrm{p}<0.01, * * * \mathrm{p}<0.001$ associations were between being drunk more than 10 times, being bullied, and having attention problems and physical aggression. Having divorced parents was the only variable not associated with physical aggression in early adolescence. One possible reason for the attenuating effect of anxiety and depression could be the combining of anxiety and depression problems in the same scale. Previous findings have shown considerable evidence for the association between depression and physical aggression [20], while the association with anxiety is more ambiguous, such that anxiety is shown to be both associated with [21] and protective against aggression [25]. Both high and low self-esteem have been found to correlate with physical aggression [29], which could be an explanation for the attenuated effect of low self-esteem in the fully adjusted, more conservative model. Having friends and participating in social activities are for many the most important part of adolescence. Being bullied has a strong association with physical aggression in early adolescence in our study. It could be that the effect of loneliness was attenuated in the fully adjusted model because bullying was a better predictor and accounted for the variance captured by loneliness. Also, experiencing loneliness could be linked to other factors, for example, lack of mutual interests, that are not necessarily associated with bullying or peer rejection and thus do not increase the risk for physical aggression.

The prevalence of physical aggression among adolescents in the present study was $17.4 \%$ in early adolescence and
9.1\% in late adolescence, which is somewhat lower than the prevalence in an American population sample [1] but still represents a profound clinical and societal challenge. The proportion in the high persistent aggression group (4.9\%) resembles high aggression groups in previous studies [3, $10,15]$. However, given differences in sample characteristics and aggression measurements between previous studies and ours, a direct comparison of our aggression courses and those in previous studies is not possible.

Our main goal in this study was to examine if risk factors in early adolescence could help explain why non-aggressive adolescents started displaying physical aggression in late adolescence, and why some adolescents continued with physically aggressive behavior while others desisted. $4.3 \%$ of the sample reported onset of physical aggression in late adolescence, which is consistent with previous studies identifying a small group of adolescents with aggressive behavior starting in adolescence [15, 31]. Our results showed that boys with attention problems and substance use (e.g. heavy drinking and smoking) in early adolescence had an increased risk of physical fighting, 4 years later in late adolescence. The predictive effect of having attention problems attenuated in the fully adjusted model, but the effect of male sex, alcohol drinking (intoxications 1-10 times), and smoking remained strong. The predictive effect of delinquent behaviors, such as drinking and smoking, early in adolescence on physical aggression starting in late adolescence could 
Table 4 Multinomial logistic regression to identify risk factors in YH1 for different aggression groups

\begin{tabular}{|c|c|c|c|c|c|c|c|c|}
\hline & \multicolumn{4}{|c|}{$\begin{array}{l}\text { The late adolescent aggression group vs the non-aggres- } \\
\text { sion group }\end{array}$} & \multicolumn{4}{|c|}{$\begin{array}{l}\text { The persistent aggression group vs the desisting } \\
\text { aggression group }\end{array}$} \\
\hline & \multicolumn{2}{|l|}{ Model 1} & \multicolumn{2}{|l|}{ Model 2} & \multicolumn{2}{|l|}{ Model 1} & \multicolumn{2}{|l|}{ Model 2} \\
\hline & ORs & $95 \% \mathrm{CI}$ & ORs & $95 \% \mathrm{CI}$ & ORs & $95 \% \mathrm{CI}$ & ORs & $95 \% \mathrm{CI}$ \\
\hline Age & 0.90 & {$[0.71,1.13]$} & 0.76 & {$[0.57,1.01]$} & 1.06 & {$[0.83,1.36]$} & 0.75 & {$[0.55,1.01]$} \\
\hline \multicolumn{9}{|l|}{ Sex } \\
\hline Boys (ref = Girls) & $4.46 * * *$ & {$[2.85,6.99]$} & $6.32 * * *$ & {$[3.72,10.72]$} & $2.22 *$ & {$[1.05,4.71]$} & 1.98 & {$[0.88,4.42]$} \\
\hline Anxiety and depression & 1.57 & {$[0.97,2.56]$} & 1.07 & {$[0.56,2.07]$} & 1.03 & {$[0.64,1.67]$} & 0.98 & {$[0.50,1.94]$} \\
\hline Loneliness & 1.23 & {$[0.97,1.54]$} & 1.13 & {$[0.84,1.51]$} & 0.93 & {$[0.73,1.19]$} & 0.88 & {$[0.65,1.19]$} \\
\hline Self-esteem prob & 1.44 & {$[0.95,2.20]$} & 1.08 & {$[0.65,1.80]$} & 0.86 & {$[0.55,1.36]$} & 0.65 & {$[0.38,1.11]$} \\
\hline Attention prob & $1.56^{*}$ & {$[1.08,2.67]$} & 1.14 & {$[0.73,1.77]$} & 1.35 & {$[0.94,1.92]$} & 1.34 & {$[0.88,2.02]$} \\
\hline Reading and writing prob & 1.03 & {$[0.80,1.32]$} & 0.92 & {$[0.70,1.21]$} & 1.14 & {$[0.92,1.42]$} & 1.09 & {$[0.86,1.38]$} \\
\hline Bullied & 0.87 & {$[0.48,1.56]$} & 0.92 & {$[0.50,1.71]$} & 1.14 & {$[0.81,1.61]$} & 1.15 & {$[0.77,1.72]$} \\
\hline \multicolumn{9}{|l|}{ Parent`s marital sit } \\
\hline $\begin{array}{l}\text { Separated or divorced } \\
\text { (ref }=\text { Together) }\end{array}$ & 1.43 & {$[0.87,2.35]$} & 1.36 & {$[0.81,2.29]$} & 1.43 & {$[0.86,2.39]$} & 1.35 & {$[0.77,2.37]$} \\
\hline \multicolumn{9}{|l|}{ Alcohol intoxication } \\
\hline $1-10$ times $(\mathrm{ref}=$ Never $)$ & $2.46^{* *}$ & {$[1.50,4.15]$} & $1.86^{*}$ & {$[1.04,3.34]$} & $2.35 * *$ & {$[1.33,4.14]$} & $2.78 * *$ & {$[1.49,5.17]$} \\
\hline$>10$ times $(\mathrm{ref}=$ Never $)$ & $4.13 * *$ & {$[1.44,11.83]$} & 1.91 & {$[0.59,6.19]$} & $4.32 * *$ & {$[1.85,10.10]$} & $5.35 * *$ & {$[1.99,14.37]$} \\
\hline \multicolumn{9}{|l|}{ Smoking } \\
\hline Yes $($ ref $=$ No) & $3.49 * * *$ & {$[1.92,6.35]$} & $2.43^{*}$ & {$[1.21,4.90]$} & 1.31 & {$[0.71,2.43]$} & 0.69 & {$[0.33,1.46]$} \\
\hline
\end{tabular}

Model 1-Associations for risk factors and physical aggression adjusted for age in YH1 and sex. Model 2-Fully adjusted model. All risk factors and covariates (age, sex) are included in the model. The non-aggression group $\mathrm{n}=1793$, the desisting aggression group $\mathrm{n}=287$, the late adolescent aggression group $\mathrm{n}=98$, and the persistent aggression group $\mathrm{n}=111$

ORs Odds Ratios, CI Confidence Interval, YHI Young-HUNT1

$* \mathrm{p}<0.05, * * \mathrm{p}<0.01, * * * \mathrm{p}<0.001$

be understood in the context of the specific characteristics of the adolescent period $[15,48,49]$. During the transition to adulthood, the influence of friends typically increases, while parental supervision decreases. Drinking alcohol and smoking in early adolescence could be associated with involvement with deviant friends, providing an accepting environment for norm-breaking behavior, which over time can increase the risk for behaviors such as physical fighting. ADHD symptoms have been shown to have a predictive effect on physical aggression [3, 5, 22]. Our results indicate that attention problems are of some relevance, but they are not an important predictor in distinguishing between nonaggressive behavior and physical aggression starting in late adolescence. It could be that the emergence of physical aggression in late adolescence is accounted for by alcohol use and smoking.

Knowing the negative consequences for the victims and the perpetrators, it is important to be able to identify the group with highly persistent aggressive behavior and know what separates this group from the other courses of aggression. In terms of developing interventions aimed at stopping physically aggressive behavior in adolescence, it is especially interesting to know what separates persistence from desistance of physical aggression. Our results showed that male sex and frequency of alcohol intoxication increased the risk of persistent aggressive behavior during adolescence but that the effect of male sex was attenuated when all of the risk factors were included, leaving heavy drinking as the sole important predictive factor separating adolescents who followed a course of persistent aggression from those who followed a course of desisting aggression. Results indicated a dose-response relationship between alcohol and aggression, as shown in previous research [43]. Recent studies on alcohol consumption have shown a declining trend in alcohol drinking among adolescents [61], which could result in declining physical aggression. However, it is unclear if the declining trend applies to all levels of consumption, especially the heavy drinking.

Results from this study regarding sex and overall age trends in physically aggressive behavior are consistent with previous studies $[6,9-11,13,15,16]$. Our results show that the prevalence of physical aggression is higher in boys than in girls and that more boys than girls are in the persistent aggression group. The prevalence of physical aggression decreased from early adolescence to late adolescence, and lower age was associated with an increased risk of physical 
aggression in the cross-sectional analysis. These findings are in line with previous studies showing a decrease in physical aggression with increasing age, thereby supporting the understanding that physical aggression is a normative part of children's development and that as children get older and mature their physical aggressive behavior decreases [11].

\section{Clinical Implications}

Physical aggression during childhood and adolescence is associated with many different risk factors, and the risk factors vary for different developmental periods. For interventions in adolescence to be effective, they need to target the relevant risk factors. Our results showed that heavy alcohol drinking in early adolescence is concurrently and longitudinally associated with aggressive behavior. Excessive alcohol drinking predicted the onset of aggressive behavior starting in late adolescence and separated persistent from desisting physical aggressive behavior over the later adolescent years. These findings highlight the need for early screening and assessment of alcohol drinking in adolescence. Taken together, the results indicate the need to identify adolescents at risk, with a specific focus on boys, as early as possible. Prevention efforts, in general, could focus on reducing alcohol drinking and smoking in early adolescence, while prevention efforts in schools could focus on facilitating mastery for students with attention and learning difficulties and on preventing bullying.

\section{Strengths and Limitations}

The major strength of the current study is the longitudinal design, the large population-based sample with a high response rate, and a dataset that allows for investigation of a wide array of correlates. In this study, we chose to examine the development of physical aggression from early to late adolescence. Examining the same adolescents at two timepoints ( $\mathrm{YH} 1$ and $\mathrm{YH} 2$ ), four years apart, provides important information on the different courses of physical aggression in adolescence and corresponding risk factors.

A limitation of the study is that the measurement for physical aggression is based on only one item assessing engagement in physical fights. However, one- item measurements of physical aggression have been used in other studies [62-64], and while more nuanced measures of aggression are commonly used in clinical populations with smaller samples, they are less used in large population-based surveys. Other forms of physical aggression were not captured in this study, which may have resulted in the lower prevalence of physical aggression in this study and affected the associations we observed. Another limitation is shared method variance, as both the dependent variable physical aggression and the risk factors were measured by self-report questionnaire and completed by the same informant. Also, we had only two timepoints ( $\mathrm{YH} 1$ and $\mathrm{YH} 2$ ) to base the aggression courses on. Additional timepoints would allow us to chart different aggression trajectories using more sophisticated, person-centered approaches (e.g., latent class growth analysis) to better probe the individual differences in aggression trajectories. Previous research suggests that SES is associated with physical aggression [10]. Our analyses adjusted for sex and age but not SES, which is a limitation. The questionnaire includes a broad range of physical and mental health variables and lifestyle factors. None of the scales or items have diagnostic precision but assess symptoms and problems. Some of the scales are shortened versions of original screening instruments, although shown to be reliable in previous studies $[57,58]$.

\section{Summary}

We identified several strong correlates of physical aggression in early adolescence including male gender, attention problems, reading and writing problems, being bullied, intensive alcohol drinking, and smoking. Different risk factors were predictive of different courses of physical aggression. For example, being male and engaging in heavy drinking and smoking during young adolescence were important predictors of physically aggressive behavior starting in late adolescence, while intensive alcohol drinking was predictive of persistent versus desisting use of physical aggression from early to late adolescence. The findings provide insights that can inform the development of preventative measures and therapeutic interventions targeting physical aggression in adolescence.

Funding This study is funded by the Department of Clinical and Molecular Medicine, Faculty of Medicine and Health Science, The Norwegian University of Science and Technology (NTNU). The study is part of a collaboration between NTNU and Yale University. The first author has received travel grants for a study stay at Child Study Center, Yale University School of Medicine, from The Liaison Committee for Education, Research and Innovation in Central Norway and Fulbright Norway. Open Access funding provided by NTNU Norwegian University of Science and Technology (incl St. Olavs Hospital - Trondheim University Hospital)

\section{Compliance with Ethical Standards}

Conflict of interest The authors have no potential conflicts of interest to declare related to the present study.

Ethical Approval The study is Data Protection Impact Assessment (DPIA) approved by The Norwegian University of Science and Technology (NTNU) and approved by the Regional Committee for Medi- 
cal and Health Research Ethics (REK) in Norway (ref. 2017/1208/ REK-midt).

Informed Consent Participation in the Young-HUNT study was voluntary. All participants gave an informed written consent to participate. For subjects under 16 years old, parents had to give consent.

Open Access This article is licensed under a Creative Commons Attribution 4.0 International License, which permits use, sharing, adaptation, distribution and reproduction in any medium or format, as long as you give appropriate credit to the original author(s) and the source, provide a link to the Creative Commons licence, and indicate if changes were made. The images or other third party material in this article are included in the article's Creative Commons licence, unless indicated otherwise in a credit line to the material. If material is not included in the article's Creative Commons licence and your intended use is not permitted by statutory regulation or exceeds the permitted use, you will need to obtain permission directly from the copyright holder. To view a copy of this licence, visit http://creativecommons.org/licenses/by/4.0/.

\section{References}

1. Kann L, McManus T, Harris WA, Shanklin SL, Flint KH, Queen B et al (2018) Youth risk behavior surveillance-United States, 2017. MMWR Surveill Summ 67(8):1. https://doi.org/10.15585/ mmwr.ss6708a1

2. Mokdad AH, Forouzanfar MH, Daoud F, Mokdad AA, El Bcheraoui C, Moradi-Lakeh M et al (2016) Global burden of diseases, injuries, and risk factors for young people's health during 19902013: a systematic analysis for the Global Burden of Disease Study 2013. The Lancet 387(10036):2383-2401. https://doi. org/10.1016/S0140-6736(16)00648-6

3. Nagin D, Tremblay RE (1999) Trajectories of boys' physical aggression, opposition, and hyperactivity on the path to physically violent and nonviolent juvenile delinquency. Child Dev 70(5):1181-1196. https://doi.org/10.1111/1467-8624.00086

4. Kokko K, Tremblay RE, Lacourse E, Nagin DS, Vitaro F (2006) Trajectories of prosocial behavior and physical aggression in middle childhood: links to adolescent school dropout and physical violence. J Res Adolesc 16(3):403-428. https://doi.org/10.111 1/j.1532-7795.2006.00500.x

5. Fontaine N, Carbonneau R, Barker ED, Vitaro F, Hebert M, Cote SM et al (2008) Girls' hyperactivity and physical aggression during childhood and adjustment problems in early adulthood: a 15-year longitudinal study. Arch Gen psychiatry. 65(3):320-328. https://doi.org/10.1001/archgenpsychiatry.2007.41

6. Odgers CL, Moffitt TE, Broadbent JM, Dickson N, Hancox RJ, Harrington $\mathrm{H}$ et al (2008) Female and male antisocial trajectories: from childhood origins to adult outcomes. Dev Psychopathol 20(2):673-716. https://doi.org/10.1017/S0954579408000333

7. Macmillan R (2001) Violence and the life course: the consequences of victimization for personal and social development. Annu Rev Sociol 27(1):1-22. https://doi.org/10.1146/annur ev.soc.27.1.1

8. Reijntjes A, Kamphuis JH, Prinzie P, Boelen PA, van der Schoot M, Telch MJ (2011) Prospective linkages between peer victimization and externalizing problems in children: a meta-analysis. Aggress Behav 37(3):215-222. https://doi.org/10.1002/ab.20374

9. Cleverley K, Szatmari P, Vaillancourt T, Boyle M, Lipman E (2012) Developmental trajectories of physical and indirect aggression from late childhood to adolescence: sex differences and outcomes in emerging adulthood. J Am Acad Child and
Adolesc Psychiatry. 51(10):1037-1051. https://doi.org/10.1016/j. jaac.2012.07.010

10. Teymoori A, Cote SM, Jones BL, Nagin DS, Boivin M, Vitaro F et al (2018) Risk factors associated with boys' and girls' developmental trajectories of physical aggression from early childhood through early adolescence. JAMA Netw Open 1(8):e186364. https ://doi.org/10.1001/jamanetworkopen.2018.6364

11. Tremblay RE (2014) Early development of physical aggression and early risk factors for chronic physical aggression in humans. Curr Top Behav Neurosci 17:315-327. https://doi. org/10.1007/7854_2013_262

12. Tremblay RE (2000) The development of agressive behaviour during childhood: what have we learned in the past century? Int J Behav Dev 24(2):129-141. https://doi.org/10.1080/0165025003 83232

13. Cote SM, Vaillancourt T, LeBlanc JC, Nagin DS, Tremblay RE (2006) The development of physical aggression from toddlerhood to pre-adolescence: a nation wide longitudinal study of Canadian children. J Abnorm Child Psychol. 34(1):71-85. https ://doi.org/10.1007/s10802-005-9001-z

14. Tremblay RE, Japel C, Perusse D, McDuff P, Boivin M, Zoccolillo M et al (1999) The search for the age of 'onset'of physical aggression: Rousseau and Bandura revisited. Crim Behav Mental Health 9(1):8-23. https://doi.org/10.1002/cbm.288

15. Brame B, Nagin DS, Tremblay RE (2001) Developmental trajectories of physical aggression from school entry to late adolescence. J Child Psychol Psychiatry 42(4):503-512 Epub 2001/06/01

16. Ehrenreich SE, Beron KJ, Brinkley DY, Underwood MK (2014) Family predictors of continuity and change in social and physical aggression from ages 9 to 18. Aggress Behav 40(5):421-439. https ://doi.org/10.1002/ab.21535

17. Valois RF, MacDonald JM, Bretous L, Fischer MA, Drane JW (2002) Risk factors and behaviors associated with adolescent violence and aggression. Am J Health Behav 26(6):454-464. https:// doi.org/10.5993/AJHB.26.6.6

18. Farrington DP, Gaffney H, Ttofi MM (2017) Systematic reviews of explanatory risk factors for violence, offending, and delinquency. Aggress Violent Behav 33:24-36. https://doi.org/10.1016/j. avb.2016.11.004

19. Angold A, Costello EJ, Erkanli A (1999) Comorbidity. J Child Psychol Psychiatry Allied Discip 40(1):57-87. https://doi. org/10.1111/1469-7610.00424

20. Dutton DG, Karakanta C (2013) Depression as a risk marker for aggression: a critical review. Aggress Violent Behav 18(2):310 319. https://doi.org/10.1016/j.avb.2012.12.002

21. Hatfield J, Dula CS (2014) Impulsivity and physical aggression: examining the moderating role of anxiety. Am J Psychol 127(2):233-243. https://doi.org/10.5406/amerjpsyc.127.2.0233

22. Reed MO, Jakubovski E, Johnson JA, Bloch MH (2017) Predictors of long-term school-based behavioral outcomes in the multimodal treatment study of children with attention-deficit/hyperactivity disorder. J Child Adolesc Psychopharmacol. 27(4):296-309. https ://doi.org/10.1089/cap.2015.0168

23. Blain-Arcaro C, Vaillancourt T (2017) Longitudinal associations between depression and aggression in children and adolescents. J Abnorm Child Psychol 45(5):959-970. https://doi.org/10.1007/ s10802-016-0204-2

24. Van der Giessen D, Branje S, Overbeek G, Frijns T, Van Lier P, Koot $\mathrm{H}$ et al (2013) Co-occurrence of aggressive behavior and depressive symptoms in early adolescence: a longitudinal multiinformant study. Revue Européenne de Psychologie Appliquée/ Eur Rev Appl Psychol 63(4):193-201. https://doi.org/10.1016/j. erap.2013.03.001

25. Murray AL, Booth T, Obsuth I, Zirk-Sadowski J, Eisner M, Ribeaud D (2018) Testing the exacerbation and attenuation 
hypotheses of the role of anxiety in the relation between ADHD and reactive/proactive aggression: a 10-year longitudinal study. Psychiatry Res 269:585-592. https://doi.org/10.1016/j.psych res.2018.08.120

26. Savage J, Ferguson CJ, Flores L (2017) The effect of academic achievement on aggression and violent behavior: a meta-analysis. Aggress Violent Behav 37:91-101

27. Savage J, Ellis SK (2019) Academic achievement, school attachment, and school problems in the differential etiology of violence. J Dev Life-Course Criminol 5(2):243-265. https://doi. org/10.1007/s40865-018-0090-0

28. Donnellan MB, Trzesniewski KH, Robins RW, Moffitt TE, Caspi A (2005) Low self-esteem is related to aggression, antisocial behavior, and delinquency. Psychol Sci 16(4):328-335. https:// doi.org/10.1111/j.0956-7976.2005.01535.x

29. Walker JS, Bright JA (2009) False inflated self-esteem and violence: a systematic review and cognitive model. J Forensic Psychiatry Pschol 20(1):1-32. https://doi.org/10.1080/1478994070 1656808

30. Farrington DP (2010) Family influences on delinquency. Juv Justice Delinq 10:203-222

31. Martino SC, Ellickson PL, Klein DJ, McCaffrey D, Edelen MO (2008) Multiple trajectories of physical aggression among adolescent boys and girls. Aggress Behav 34(1):61-75. https://doi. org/10.1002/ab.20215

32. Barnow S, Lucht M, Freyberger HJ (2001) Influence of punishment, emotional rejection, child abuse, and broken home on aggression in adolescence: an examination of aggressive adolescents in Germany. Psychopathology 34(4):167-173. https://doi. org/10.1159/000049302

33. Bierman KL (2004) Peer rejection: developmental processes and intervention strategies. Guilford Press, New York

34. Ostrov JM, Murray-Close D, Godleski SA, Hart EJ (2013) Prospective associations between forms and functions of aggression and social and affective processes during early childhood. J Exp Child Psychol 116(1):19-36. https://doi.org/10.1016/j. jecp.2012.12.009

35. Lansford JE, Malone PS, Dodge KA, Pettit GS, Bates JE (2010) Developmental cascades of peer rejection, social information processing biases, and aggression during middle childhood. Dev Psychopathol 22(3):593-602. https://doi.org/10.1017/S0954 579410000301

36. Demuth S (2004) Understanding the delinquency and social relationships of loners. Youth Soc 35(3):366-392. https://doi. org/10.1177/0044118x03255027

37. Ttofi MM, Farrington DP, Losel F (2012) School bullying as a predictor of violence later in life: a systematic review and metaanalysis of prospective longitudinal studies. Aggress Violent Behav 17(5):405-418. https://doi.org/10.1016/j.avb.2012.05.002

38. Farrington DP (2007) Origins of violent behavior over the life span. In: Flannery DJ, Vazsonyi AT, Waldman ID (eds) The Cambridge handbook of violent behavior and aggression. Cambridge University Press, Cambridge, pp 19-48

39. Froyland LR, von Soest T (2018) Trends in the perpetration of physical aggression among Norwegian adolescents 2007-2015. J Youth Adolesc 47(9):1938-1951. https://doi.org/10.1007/s1096 4-017-0793-2

40. Tomlinson MF, Brown M, Hoaken PNS (2016) Recreational drug use and human aggressive behavior: a comprehensive review since 2003. Aggress Violent Beh 27:9-29. https://doi.org/10.1016/j. avb.2016.02.004

41. White HR, Brick J, Hansell S (1993) A longitudinal investigation of alcohol use and aggression in adolescence. J Stud Alcohol Suppl 11:62-77. https://doi.org/10.15288/jsas.1993.s11.62
42. Skara S, Pokhrel P, Weiner MD, Sun P, Dent CW, Sussman S (2008) Physical and relational aggression as predictors of drug use: gender differences among high school students. Addict Behav 33(12):1507-1515. https://doi.org/10.1016/j.addbeh.2008.05.014

43. Wells S, Mihic L, Tremblay PF, Graham K, Demers A (2008) Where, with whom, and how much alcohol is consumed on drinking events involving aggression? Event-level associations in a Canadian national survey of university students. Alcoholism 32(3):522-533. https://doi.org/10.1111/j.1530-0277.2007.00596 $\mathrm{x}$

44. Lipsey MW, Derzon JH (1998) Predictors of violent or serious delinquency in adolescence and early adulthood: a synthesis of longitudinal research. In: Loeber R, Farrington DP (eds) Serious $\&$ violent juvenile offenders: Risk factors and successful interventions. Sage Publications Inc, Thousand Oaks, pp 86-105

45. Moffitt TE (2018) Male antisocial behaviour in adolescence and beyond. Nat Hum Behav 2(3):177-186. https://doi.org/10.1038/ s41562-018-0309-4

46. Bolhuis K, Lubke GH, van der Ende J, Bartels M, van Beijsterveldt CEM, Lichtenstein P et al (2017) Disentangling heterogeneity of childhood disruptive behavior problems into dimensions and subgroups. J Am Acad Child Adolesc Psychiatry 56(8):678 686. https://doi.org/10.1016/j.jaac.2017.05.019

47. O'Donnell L, Stueve A, Myint-U A, Duran R, Agronick G, Wilson-Simmons R (2006) Middle school aggression and subsequent intimate partner physical violence. J Youth Adolesc 35(5):693703. https://doi.org/10.1007/s10964-006-9086-x

48. Martel A, Fuchs DC (2017) Transitional age youth and mental illness-influences on young adult outcomes. Child Adolesc Psychiatr Clin N Am. 26(2):xiii-xvii. https://doi.org/10.1016/j. chc.2017.01.001

49. Leebens PK, Williamson ED (2017) Developmental psychopathology: risk and resilience in the transition to young adulthood. Child Adolesc Psychiatr Clin N Am 26(2):143-156. https://doi. org/10.1016/j.chc.2016.12.001

50. Stoddard SA, Whiteside L, Zimmerman MA, Cunningham RM, Chermack ST, Walton MA (2013) The relationship between cumulative risk and promotive factors and violent behavior among urban adolescents. Am J Commun Psychol 51(1-2):57-65. https ://doi.org/10.1007/s10464-012-9541-7

51. Hsieh H-F, Zimmerman MA, Bauermeister JA, Caldwell CH, Xue $\mathrm{Y}$, Wang $\mathrm{Z}$ et al (2016) Cumulative risks and promotive factors for Chinese adolescent problem behaviors. J Appl Dev Psychol 43:71-82. https://doi.org/10.1016/j.appdev.2016.01.003

52. Holmen TL, Bratberg G, Krokstad S, Langhammer A, Hveem $\mathrm{K}$, Midthjell $\mathrm{K}$ et al (2014) Cohort profile of the Young-HUNT Study, Norway: a population-based study of adolescents. Int J Epidemiol 43(2):536-544. https://doi.org/10.1093/ije/dys232

53. Krokstad S, Langhammer A, Hveem K, Holmen TL, Midthjell K, Stene TR et al (2013) Cohort profile: the HUNT study Norway. Int J Epidemiol 42(4):968-977. https://doi.org/10.1093/ije/dys09 5

54. Skrove M, Romundstad P, Indredavik MS (2015) Chronic multisite pain in adolescent girls and boys with emotional and behavioral problems: the Young-HUNT study. Eur Child Adolesc Psychiatry 24(5):503-515. https://doi.org/10.1007/s00787-014-0601-4

55. Storksen I, Roysamb E, Moum T, Tambs K (2005) Adolescents with a childhood experience of parental divorce: a longitudinal study of mental health and adjustment. J Adolesc. 28(6):725-739. https://doi.org/10.1016/j.adolescence.2005.01.001

56. Strandheim A, Holmen TL, Coombes L, Bentzen N (2009) Alcohol intoxication and mental health among adolescents-a population review of 8983 young people, 13-19 years in North-Trondelag, Norway: the Young-HUNT Study. Child Adolesc Psychiatry Mental Health 3(1):18. https://doi.org/10.1186/1753-2000-3-18 
57. Strand BH, Dalgard OS, Tambs K, Rognerud M (2003) Measuring the mental health status of the Norwegian population: a comparison of the instruments SCL-25, SCL-10, SCL-5 and MHI-5 (SF-36). Nordic J Psychiatry. 57(2):113-118. https://doi. org/10.1080/08039480310000932

58. Tambs K, Moum T (1993) How well can a few questionnaire items indicate anxiety and depression? Acta Psychiatr Scand 87(5):364 367. https://doi.org/10.1111/j.1600-0447.1993.tb03388.x

59. Rosenberg M (1965) Society and the adolescent self-image. Princeton University, Princeton

60. Alessandri G, Vecchione M, Eisenberg N, Laguna M (2015) On the factor structure of the Rosenberg (1965) General Self-Esteem Scale. Psychol Assess 27(2):621-635. https://doi.org/10.1037/ pas0000073

61. Pape H, Rossow I, Brunborg GS (2018) Adolescents drink less: how, who and why? A review of the recent research literature. Drug Alcohol Rev 37:S98-S114. https://doi.org/10.1111/ dar.12695
62. Duke NN, Pettingell SL, McMorris BJ, Borowsky IW (2010) Adolescent violence perpetration: associations with multiple types of adverse childhood experiences. Pediatrics 125(4):e778-e786. https://doi.org/10.1542/peds.2009-0597

63. Nivette A, Sutherland A, Eisner M, Murray J (2019) Sex differences in adolescent physical aggression: evidence from sixty-three low-and middle-income countries. Aggress Behav 45(1):82-92. https://doi.org/10.1002/ab.21799

64. Pickett W, Molcho M, Elgar FJ, Brooks F, De Looze M, Rathmann $\mathrm{K}$ et al (2013) Trends and socioeconomic correlates of adolescent physical fighting in 30 countries. Pediatrics 131(1):e18-e26. https ://doi.org/10.1542/peds.2012-1614

Publisher's Note Springer Nature remains neutral with regard to jurisdictional claims in published maps and institutional affiliations. 